\title{
Mössbauer Investigation of the Electronic Structure of the "Brown-ring" Complex
}

\author{
H. MOSB $Æ K$ and K. G. POULSEN \\ Chemistry Department A, The Technical University of Denmark, Lyngby, Denmark
}

\begin{abstract}
Investigation of mononitrosyl iron complexes $-\left[\mathrm{Fe}(\mathrm{NO}) \mathrm{L}_{5}\right]^{2+}-$ with Mössbauer- and IR-spectroscopy indicates the electronic structure of these compounds to be $\left(e^{b}\right)^{4}\left(b_{2}\right)^{1}\left(b_{1}{ }^{*}\right)^{1}\left(a_{1}{ }^{*}\right)^{1}$.
\end{abstract}

$\mathrm{T}^{\mathrm{h}}$

he electronic structure of the complex ion $\left[\mathrm{Fe}(\mathrm{NO})\left(\mathrm{H}_{2} \mathrm{O}\right)_{5}\right]^{2+}$ has attracted considerable interest, ${ }^{1-4}$ the reason being of course the difficulties encountered when trying to discuss the charge distribution in the molecule. This situation, which is general for most $\mathrm{NO}$-complexes, is due to the versatility of the NO-ligand, which formally has the ability to exhibit the oxidation numbers $-1,0$, and +1 .

Determination of the NO-stretch force constant has often been used as a means of assigning an "oxidation number" to the NO-part of such complexes. However, this is not a safe method. According to the work by Lewis et al..$^{5}$ the force constant for $\mathrm{NO}$ bound as $\mathrm{NO}^{+}$has values between the limits 11.4 and $16.8 \mathrm{mdyn} / \AA$. But, as mentioned by Gans, ${ }^{6}$ this is according to Table 1 closer to the values expected for $\mathrm{NO}$ and $\mathrm{NO}^{-}$.

Magnetic measurements led Griffith et al.1 to describe the "brown-ring complex" as a high-spin compound having 3 unpaired electrons without any metal-NO $\pi$-bonding. In Table 2 are shown magnetic moments and IR force constants for some complexes, which according to their magnetic moments should have an electronic structure equivalent to that of the "brown-ring complex". In the following all these complexes will be described under the general term brown-ring complexes.

In Table 2 are also given the IR stretch force constants, and it can be seen by a comparison with Table 1 , that the NO-part of the complexes must have an electron density distribution, which is somewhere between that found for $\mathrm{NO}^{\circ}$ and $\mathrm{NO}^{-}$, i.e. there is an electron density in the $\pi^{*}$-orbitals af NO corresponding to $1-2$ electrons.

The following descriptions of the orbitals in the complexes are used according to their transformation properties in $C_{4 v}$-symmetry: $d_{z}^{2}: a_{1} ; d_{x^{2}-y^{2}}: b_{1}$; $d_{x y}: b_{2} ; d_{x z}, d_{y_{z}}, \pi^{*}(\mathrm{NO}): e$.

Acta Chem. Scand. 25 (1971) No. 7 
Table 1. Force constants for NO-compounds. ${ }^{a}$

\begin{tabular}{ll}
\hline Compound & $k_{\mathrm{NO}}(\operatorname{mdyn} / \AA)$ \\
\hline$\left(\mathrm{NO}^{+}\right)\left(\mathrm{HSO}_{4}{ }^{-}\right)$ & 25.0 \\
$\mathrm{NO}^{-}\left(\mathrm{O}_{2}\right)$ & 15.5 \\
\hline
\end{tabular}

a From Ref. 7.

Table 2. Magnetic moments and force constants for NO in brown-ring complexes. ${ }^{a}$

\begin{tabular}{|c|c|c|c|}
\hline Compound & $\mu_{\mathrm{B}}$ & $k_{\mathrm{NO}}(\mathrm{mdyn} / \AA)$ & Ref. \\
\hline $\begin{array}{l}\mathrm{Fe}(\mathrm{NO})^{2+} \text { in } \mathrm{H}_{2} \mathrm{O} \\
\mathrm{Fe}(\mathrm{NO})\left(\mathrm{NH}_{3}\right)_{5} \mathrm{Cl}_{2} \\
\mathrm{Fe}(\mathrm{NO})_{\text {salen }} \\
\mathrm{Fe}(\mathrm{NO}) \text { sal }_{2} \text { py } \\
\text { Temperature ca. } 2^{\circ} \mathrm{C} .\end{array}$ & $\begin{array}{r}3.9 \\
<4.7 \\
3.8 \\
4.0\end{array}$ & $\begin{array}{l}14.2 \\
13.6 \\
12.9 \\
13.0\end{array}$ & $\begin{array}{r}1 \\
8 \\
\mathbf{9} \\
10\end{array}$ \\
\hline
\end{tabular}

a The following abbreviations are used in this paper: salen: $N, N^{\prime}$ ethylene bis(salicylideneimine); sal: salicylaldehyde; py: pyridine.

Manoharan and Gray ${ }^{11}$ have made Wolfsberg-Helmholtz calculations on several pentacyanonitrosyl complexes. For the nitroprusside, they found a $25 \%$ involvement of the $\pi^{*}$ (NO) orbitals in the two $e$ orbitals of iron, and nitroprusside turned out to be the case with the weakest such admixture. From this it must be expected that NO-complexes are characterized by a very marked $\pi$-bonding between the $3 d$-orbitals of the central atom and the $\pi^{*}$ orbitals of NO.

\section{EXPERIMENTAL}

Mössbauer spectroscopy has been shown to be a powerful tool in the evaluation of the oxidation number of iron in high-spin complexes. ${ }^{12-15}$

The Mössbauer spectra of several of the compounds in Table 2 have been obtained at $c a .25^{\circ} \mathrm{C}$ as well as at lower temperatures, usually at the boiling point of nitrogen. The apparatus has been described previously. ${ }^{16}$ The parameters of the spectra are shown in Table 3, and some of the spectra in Figs. 1-3. Regarding the $\left[\mathrm{Fe}(\mathrm{NO})\left(\mathrm{H}_{2} \mathrm{O}\right)_{5}\right]^{2+}$. compound, two spectra are shown. This is due to the fact, that two different species have been produced. The one shown in Fig. 1 is prepared according to the method of Manchot, ${ }^{8}$ but the content of NO in the compound described - which was formulated $\mathrm{Fe}(\mathrm{NO}) \mathrm{SO}_{4} \cdot \mathrm{FeSO}_{4} \cdot 13 \mathrm{H}_{2} \mathrm{O}$ - was found by us to be less than calculated from the formula. The Mössbauer spectrum was reminiscent of the spectrum of $\mathrm{FeSO}_{4} .7 \mathrm{H}_{2} \mathrm{O}$, the only difference being a small peak at $2.1 \mathrm{~mm} / \mathrm{sec}$. By coincidence it was found that continued administration of NO to the complex resulted in a new compound, in which the NO/Fe ratio was found to be much higher, (approx. 0.8). The spectrum of this compound is shown in Fig. 2. It was not possible to reproduce the spectrum obtained by Danon, ${ }^{17}$ but the two spectra (Figs. 1 and 2) show great similarity. Only the portion due 
Table 3. Mössbauer parameters for some iron compounds.

\begin{tabular}{|c|c|c|c|}
\hline & $\begin{array}{c}\text { Isomer shift }^{a} \\
\mathrm{~mm} / \mathrm{s}\end{array}$ & $\begin{array}{c}\text { Quadrupole } \\
\text { splitting } \\
\mathrm{mm} / \mathrm{s}\end{array}$ & $\begin{array}{c}\text { Temperature } \\
{ }^{\circ} \mathrm{C}\end{array}$ \\
\hline $\mathrm{Fe}(\mathrm{NO}) \mathrm{SO}_{4} \mathrm{FeSO}_{4} \cdot 13 \mathrm{H}_{2} \mathrm{O}$ & ca. 1.2 & ca. 2.0 & 0 \\
\hline $\mathrm{Fe}(\mathrm{NO}) \mathrm{SO}_{4} \cdot \mathrm{aq}$ & 1.02 & 2.31 & -170 \\
\hline $\mathrm{Fe}(\mathrm{NO})\left(\mathrm{NH}_{3}\right)_{5} \mathrm{Cl}_{2}$ & 0.95 & 1.36 & -170 \\
\hline $\mathrm{Fe}(\mathrm{NO})$ salen & 0.68 & 0.69 & 80 \\
\hline $\mathrm{FeCl}(\text { in } \mathrm{NaCl})^{b}$ & 2.2 & & 22 \\
\hline $\mathrm{Fe}\left(\mathrm{SO}_{4} .7 \mathrm{H}_{2} \mathrm{O}\right.$ & 1.53 & & 22 \\
\hline $\mathrm{Fe}_{2}\left(\mathrm{SO}_{4}\right)_{3} \cdot \mathrm{aq}$ & 0.74 & & 22 \\
\hline
\end{tabular}

a Relative to sodium nitroprusside.

$b$ From Ref. 13.

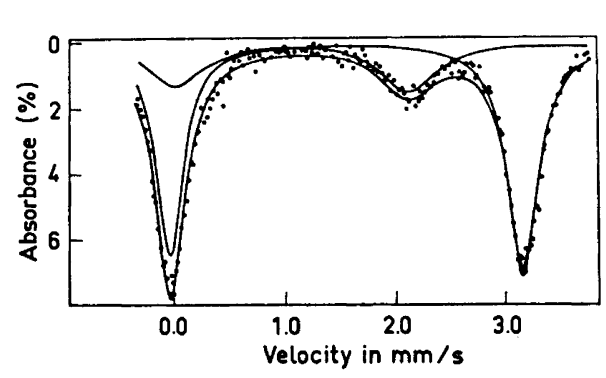

Fig. 1. Mössbauer spectrum of $\mathrm{Fe}(\mathrm{NO}) \mathrm{SO}_{4} \cdot 13 \mathrm{H}_{2} \mathrm{O}$ at $0^{\circ} \mathrm{C}$.

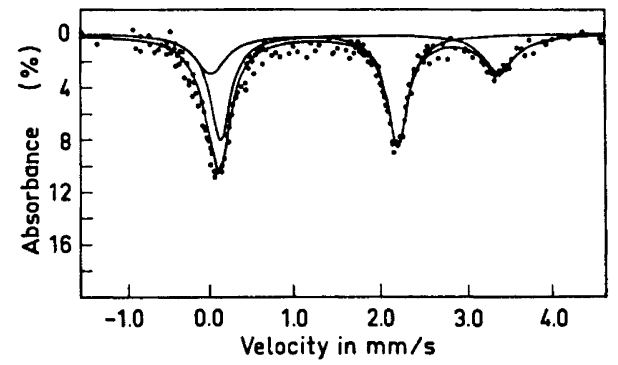

Fig. 2. Mössbauer spectrum of $\mathrm{Fe}(\mathrm{NO}) \mathrm{SO}_{4}$.aq. at $-170^{\circ} \mathrm{C}$.

to $\mathrm{Fe}(\mathrm{NO})^{2+}$ is less in the former spectrum, where one of the peaks moreover is hidden under the low energy peak of $\mathrm{FeSO}_{4} \cdot 7 \mathrm{H}_{2} \mathrm{O}$. The other compounds were made according to literature, ${ }^{18,9}$ and analysed by standard methods; the NO content was determined by the Dumas method, except for the "salen" compound where it was obtained by thermogravimetric analysis. (Found: $\mathrm{Fe} 22.8 ; \mathrm{NH}_{3} 35.0 ; \mathrm{Cl}$ 29.0. Calc. for $\mathrm{Fe}(\mathrm{NO})\left(\mathrm{NH}_{3}\right)_{5} \mathrm{Cl}_{2}: \mathrm{Fe} 23.1 ; \mathrm{NH}_{3}$ 35.2; $\mathrm{Cl}$ 29.3.) (Found: $\mathrm{Fe}$ 15.7; NO 8.0. Calc. for $\mathrm{Fe}(\mathrm{NO})$ salen: $\mathrm{Fe}$ 15.4; $\mathrm{NO}$ 8.3.) All the results have been treated at the Northern Europe University Computing Center with a programme using least squares treatment.

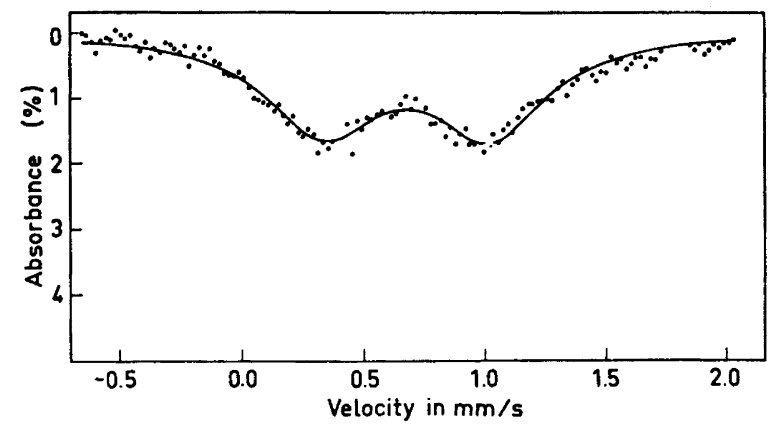

Fig. 3. Mössbauer spectrum of $\mathrm{Fe}(\mathrm{NO})$ salen at $-80^{\circ} \mathrm{C}$.

Acta Chem. Scand. 25 (1971) No. 7 


\section{DISCUSSION}

In Table 3 are presented the isomer shifts of typical high-spin iron compounds in the oxidation state 1,2 , and 3 . In such compounds the isomer shift will, to a first approximation, be dependent only on the electron density in the $3 d$-orbitals. Accordingly, we can use Mössbauer spectroscopy in the same way as the IR force constant to determine the charge distribution in the complexes. However, it is not possible to derive the electronic structure from the isomer shift alone, since all the valence orbitals of the complex should be considered. The electron distribution among these orbitals should therefore be chosen in agreement with the information from magnetic measurements $(S=3 / 2)$ and from the isomer shifts ( $3 d$-electron density between that of $\mathrm{Fe}(\mathrm{II})$ and $\mathrm{Fe}(\mathrm{III}))$. In Table 4 are shown the available orbitals together with a characterization for these orbitals.

Table 4:

\begin{tabular}{ccr}
\hline Orbital & Expression & \\
\hline$a_{1}{ }^{b}$ & $\alpha_{1} d_{a_{1}}+\sqrt{1-\alpha_{1}^{2}} \sigma_{\mathrm{Lig}, a_{1}}$ & $\sigma$-bonding \\
$b_{1}{ }^{b}$ & $\alpha_{2} d_{b_{1}}+\sqrt{1-\alpha_{2}{ }^{2}} \sigma_{\mathrm{Lig}, b_{1}}$ & $\sigma$-bonding \\
$e^{b}$ & $a_{c}+\sqrt{1-a^{2}} \pi^{*}$ NO & $\pi$-bonding \\
$b_{2}$ & $d_{x y}$ & non-bonding \\
$a_{1}{ }^{*}$ & $\sqrt{1-\alpha_{1}{ }^{2}} d_{a_{1}}-\alpha_{1} \sigma_{\mathrm{Lig}, a_{1}}$ & $\sigma$-antibonding \\
$b_{1}{ }^{*}$ & $\sqrt{1-\alpha_{2}^{2}} d_{b_{1}}-\alpha_{2} \sigma_{\mathrm{Lig}, b_{1}}$ & $\sigma$-antibonding \\
$e^{*}$ & $\sqrt{1-a^{2}} d_{e}-a_{\cdot} \cdot \pi^{*}$ NO & $\pi$-antibonding \\
\hline
\end{tabular}

$\sigma_{\mathrm{Lig}}$ represents the proper linear combination of ligand orbitals.

$b_{2}$ is considered non-bonding since the equatorial ligands in this investigation have only neglectable $\pi$-bonding capacity. In the table are omitted the $4 s$ and $4 p$-orbitals as these orbitals can be assumed to have negligible importance in the following calculations. The relative positions of the orbitals in Table 4 have been widely discussed. ${ }^{4},{ }^{9},{ }^{10-21}$ First regarding the $S=3 / 2$ ground state, it will be profitable to divide the available orbitals in 2 parts, first the bonding orbitals, and secondly the non-bonding and the antibonding orbitals. The bonding orbitals are supposed to be placed at an energy, so low that they will be completely filled. The 3 unpaired electrons must then be distributed among the non-bonding and the antibonding orbitals. Moreover, it will be assumed that the non-bonding orbital is placed at a lower energy than the antibonding ones. Using these assumptions and the data from magnetic measurements there are only 4 possible electron configurations, all of which are listed in Table 5.

In order to distinguish between the different configurations the quadrupole splittings have been calculated for these. In the summation of the one-electron contributions according to the expression in Table 4, the values given by 
Table 5. Electron configurgtions for brown-ring complexes with $S=3 / 2$.

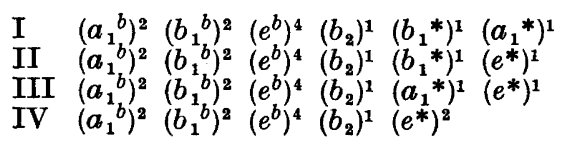

Johnson et $a l .{ }^{22}$ have been used. In the calculations of the quadrupole splittings shown in Table 6 only electron density in the immediate neighbourhood of the iron nucleus is regarded. This is founded in the $r^{-3}$-dependence of the electric field gradient. Furthermore, the same radial dependence is assumed for all the $3 d$-orbitals.

Table 6. Relative magnitude of the quadrupole splitting for diffent electronic configurations in brown-ring complexes.

Configuration Quadrupole splitting

$\begin{array}{lr}\text { I } & 4-8 a^{2}-4 \alpha_{1}{ }^{2}+4 \alpha_{2}{ }^{2} \\ \text { III } & 6-6 a^{2}-8 \alpha_{1}{ }^{2}+4 \alpha_{2}{ }^{2} \\ \text { III } & -2-6 a^{2}+8 \alpha_{2}{ }^{2}-4 \alpha_{1}{ }^{2} \\ \text { IV } & -4 a^{2}+8 \alpha_{2}{ }^{2}-8 \alpha_{1}{ }^{2}\end{array}$

Before any conclusion can be drawn from Table 6 the parameters in the expressions must be discussed. The value of $a^{2}$ is most easily determined. From the IR force constant the electron density in $\pi^{*}(\mathrm{NO})$ orbitals can be calculated and using the expressions for the orbitals used $a^{2}$ can be found. $a^{2}$ could as well be derived by a comparison of the isomer shift found with the isomer shift of "normal" $\mathrm{Fe}(\mathrm{II})$ and Fe(III) compounds. However, using this method the $\sigma$-bonding in the complexes could influence the result so it is considered to be a better way to use IR data. In Table 7 are given the calculated values for $a^{2}$ for the aquo and the salen complexes. The ammonia compound is in every respect situated between these two.

It is a much more difficult task to calculate the values of $\alpha_{1}{ }^{2}$ and ${\alpha_{2}}^{2}$, both connected with the $\sigma$-bonding in the complexes. First, the 2 parameters will be considered equal. Neither $\mathrm{H}_{2} \mathrm{O}$ nor salen are expected to have strong

Table 7. Calculated quadrupole splittings for $\mathrm{Fe}(\mathrm{NO})\left(\mathrm{H}_{2} \mathrm{O}\right)_{5}{ }^{2+},(\mathrm{A})$ and $\mathrm{Fe}(\mathrm{NO})$ salen, (B).

\begin{tabular}{|c|c|c|c|c|c|c|}
\hline \multirow[t]{2}{*}{ Configuration } & \multicolumn{2}{|c|}{$a^{2}$} & \multicolumn{4}{|c|}{ Quadrupole splitting } \\
\hline & A & $\mathbf{B}$ & $\alpha^{2}=0.2$ & $\alpha^{2}=0.3$ & $\alpha^{2}=0.2$ & $\alpha^{2}=0.3$ \\
\hline I & 0.7 & 0.5 & -1.4 & -1.4 & -0.6 & -0.6 \\
\hline II & 0.9 & 0.8 & -0.2 & -0.6 & 0.8 & 0.4 \\
\hline III & 0.9 & 0.8 & -6.6 & -6.2 & -5.8 & -5.4 \\
\hline IV & - & 1.0 & - & - & 4. & 4. \\
\hline
\end{tabular}

Acta Chem. Scand. 25 (1971) No. 7 
$\sigma$-bonding. From a comparison with $\mathrm{CO}$, which is a weak Lewis base, the same is expected for the isoelectronic ligand $\mathrm{NO}^{+}$. Furthermore, even a slight difference in the bonding capacity will be averaged as $a_{1}$ makes $\sigma$-bonds to all the 6 ligands.

By investigations of eigenvectors obtained from Wolfsberg-Helmholtz calculations and $\beta$-values calculated from absorption spectra of similar compounds it is believed that 0.3 is an upper limit of $\alpha^{2}\left(=\alpha_{1}^{2}=\alpha_{2}^{2}\right)$ in these complexes. The calculations of the relative magnitude of the quadrupole splittings for the aquo and the salen compound have been carried out using $\alpha^{2}=0.2$ as well as $\alpha^{2}=0.3$. It can be seen from Table 7 that a change in this parameter has a minor influence only.

From a comparison of the experimental and the calculated quadrupole splittings it follows that configuration $I$ is the only one which gives a reasonable conformity.

The lack of values for configuration IV is due to the impossibility of achieving electron density in $\pi^{*}(\mathrm{NO})$ smaller than that corresponding to 2 electrons when using the orbitals specified in Table 4. An inclusion of the overlap in the calculation may change this fact, but it is considered unlikely that such an extension of the calculations would give quadrupole splittings in any agreement with the experimental ones.

The result of the discussion indicates clearly that the electronic structure of the brown-ring complexes should be described as $\left(a_{1}^{b}\right)^{2}\left(b_{1}^{b}\right)^{2}\left(e^{b}\right)^{4}\left(b_{2}\right)^{1}\left(b_{1}{ }^{*}\right)^{1}$ $\left(a_{1}^{*}\right)^{1}$. The charge distribution at the iron nucleus is - especially in the ammonia and the salen compound - rather close to +3 as found before. ${ }^{16}$ An assignment of an "oxidation number" to the central atom in the compounds would be possible using the method outlined by Manoharan and Gray.11

The above results should not be applied to other compounds where the equatorial ligands are placed higher in the spectrochemical series. ${ }^{23}$ This will change the position of $b_{1}^{*}$ towards higher energies and thereby causing an inversion of the orbitals as found in nitroprusside. ${ }^{11}$

\section{REFERENCES}

1. Griffith, W. P., Lewis, J. and Wilkinson, G. J. Chem. Soc. 19583993.

2. Jørgensen, C. K. Inorganic Complexes, Academic, London 1963, p. 126.

3. Manchot, W. Z. anorg. allgem. Chem. 140 (1924) 22.

4. Gray, H. B., Bernal, I. and Billig, E. J. Am. Chem. Soc. 84 (1962) 3404.

5. Lewis, J., Irving, R. J. and Wilkinson, G. J. Inorg. Nucl. Chem. 7 (1958) 32.

6. Gans, P. Chem. Commun. 1965144.

7. Shamir, J., Binenboym, J. and Claassen, Howard H. J. Am. Chem. Soc. 90 (1968) 6223.

8. Rindorf, G., Mosbæk, H. and Poulsen, K. G. Acta Chem. Scand. 24 (1970) 742.

9. Earnshaw, A., King, E. A. and Larkworthy, L. F. J. Chem. Soc. A 19692459.

10. Nast, R. and Rückemann, H. Z. anorg. allgem. Chem. 307 (1961) 308.

11. Manoharan, P. T. and Gray, H. B. Inorg. Chem. 5 (1966) 823.

12. Fluck, E., Kerler, W. and Neuwirth, W. Angew. Chem. 75 (1963) 461.

13. Mullen, J. G. Phys. Rev. 131 (1963) 1415.

14. Brown, D. B., Shriver, D. F. and Schwartz, L. H. Inorg. Chem. 7 (1968) 77.

15. Moss, T. H., Ehrenberg, A. and Bearden, A. J. Biochemistry 8 (1969) 4159.

16. Mosbæk, H. and Poulsen, K. G. Chem. Commun. 1969479. 
17. Danon, J. J. Chem. Phys. 41 (1964) 3378.

18. Weitz, E. and Müller, H. Angəw. Chem. 62 (1950) 221.

19. Frank, E. and Abeledo, C. R. J. Inorg. Nucl. Chem. 31 (1969) 989.

20. Johnson, C. E., Rickards, R. and Hill, H. A. O. J. Chem. Phys. 50 (1969) 2594.

21. Hockings, E. F. and Bernal, I. J. Chem. Soc. 19645029.

22. Dale, B. W., Williams, R. J. P., Edvards, P. R. and Johnson, C. E. J. Chem. Phys. 49 (1968) 3445.

23. Ballhausen, C. J. Introduction to Ligand Field Theory, McGraw, New York 1962, p. 91.

Received November 9, 1970. 